REVISTA X, Curitiba, volume 14, n.4,p. 107-119, 2019

\title{
REFLEXÕES SOBRE A IDENTIDADE DE PESSOAS TRANS EM NOTÍCIAS ONLINE: UMA ANÁLISE DO CONTEÚDO TEMÁTICO
}

Reflections on the identity of trans people in online news: an analysis of the thematic content

\section{Maria Lígia Freire GUILHERME - UFSC ${ }^{1}$}

\begin{abstract}
RESUMO: A presente pesquisa busca analisar os modos como questões referentes à identidade de sujeitos trans são discursivizadas em notícias online a partir de seus conteúdos temáticos. Para tanto, tomou-se o Decreto $\mathrm{N}^{\circ} 8.727$ como ponto de partida, além de dez notícias do jornalismo online. O olhar para os dados fez emergir algumas regularidades a respeito da discursivização da identidade de sujeitos trans, sendo essa por vezes rejeitada ou não reconhecida. Este estudo se deu por meio de uma Análise Dialógica do Discurso (ADD), ancorada teóricometodologicamente nos estudos do Círculo de Bakhtin.
\end{abstract}

PALAVRAS-CHAVE: Identidade; Pessoa trans; Notícia online; Conteúdo temático; Círculo de Bakhtin.

\begin{abstract}
The present research aims to analyze the ways in which issues related to the identity of trans people are discussed in online news from their thematic contents. To do so, we took Decree No. 8.727 as a starting point, as well as 10 online journalism news. The look at the data gave rise to some regularities regarding the discursivization of trans people identity, which is sometimes rejected or unrecognized. This study was carried out through a Dialogical Discourse Analysis (ADD), anchored theoretically-methodologically in the studies of the Bakhtin Circle.
\end{abstract}

KEYWORDS: Identity; Trans people; Online news; Thematic Content; Bakhtin Circle.

\section{INTRODUÇÃO}

Este estudo se volta para questões concernentes à identidade social de pessoas trans, buscando compreender como essa se constitui em notícias online por meio de uma análise dialógica do discurso (ADD) que tomou como ponto de partida o conteúdo temático dez notícias veiculadas após a publicação do Decreto $\mathrm{N}^{\circ} 8.727$, que versa sobre o nome social de pessoas trans na esfera pública federal. Para tanto, foram

\footnotetext{
1 Doutoranda em Linguística pela Universidade Federal de Santa Catarina (UFSC), na área de concentração de Linguística Aplicada, mestra em Estudos de Linguagens (2017) pela Universidade Tecnológica Federal do Paraná (UTFPR), universidade em que se licenciou em Letras Português-Inglês (2015) e onde atua como Técnica Administrativa em Educação desde 2015. E-mail: marialigiafreire@gmail.com
} 
acionados os estudos bakhtinianos a respeito da linguagem. Na perspectiva dos estudos do Círculo de Bakhtin, a linguagem é compreendida para além de um objeto isolado da Linguística e é vista como um lugar de ação e interação entre sujeitos (BAKHTIN; VOLOCHÍNOV, 2014[1929]). Um dos elementos mais importantes nessa compreensão é justamente o fator social que permeia e atravessa a linguagem, fator esse indispensável para que o complexo físico, psíquico e psicológico que a constitui se concretize, como afirmam Bakhtin e Volochínov (2014[1929], p. 73):

[a]ssim como, para observar o processo de combustão, convém colocar o corpo no meio atmosférico, da mesma forma, para observar o fenômeno da linguagem, é preciso situar os sujeitos - emissor e receptor do som -, bem como o próprio som, no meio social.

Assim, para percorrer e bem compreender o pensamento bakhtiniano, deve-se levar em conta a natureza dialógica e sócio-ideológica da linguagem proposta pelos autores do Círculo. Para o Círculo, ideologia é um construto social, que se constitui a partir das relações entre os indivíduos e se manifesta, necessariamente, pela linguagem. Para Volochínov (2013[1930], p. 193), “a palavra, por sua própria natureza intrínseca, é desde o início um fenômeno puramente ideológico. Toda realidade objetiva da palavra consiste exclusivamente na sua destinação de ser um signo". Ainda, nessa perspectiva, os conceitos se entrelaçam, ou seja, "para falar em língua há que se falar em enunciado, para falar em enunciado há que se falar em discurso e assim, sucessivamente, os conceitos se sobrepõem e dialogam entre si" (GUILHERME, 2017, p. 26). Dito isso, nos referimos à língua(gem $)^{2}$ como sendo conceito equivalente ao de discurso, entendido como a língua em sua integridade concreta e viva (BAKHTIN, 2015[1963]), permeado por relações dialógicas e que se manifesta por meio de enunciados (BAKHTIN, 2015[1979]).

O enunciado é, portanto, a materialização dos discursos e ideologias dos sujeitos e um produto da atividade humana, que reflete os elementos da sociedade em que se enuncia (VOLOCHÍNOV, 2013[1930]). É por meio dos enunciados que a vida interior do homem e sua consciência se organizam. Para Bakhtin (2016[1952-1953]), os enunciados são constituídos por três elementos principais: conteúdo temático, estilo e construção composicional, elementos esses conectados de modo indissolúvel e

2 Nesta pesquisa, tal qual na perspectiva teórica aqui assumida, utilizamos os termos língua e linguagem como intercambiáveis. 
determinados pelas peculiaridades do campo de atividade humana em que se inserem. Sendo assim, tomamos os enunciados como objetos de análise da presente pesquisa.

Neste artigo $^{3}$, analisamos onze enunciados, das esferas jurídico-governamental e jornalística que abordam a questão do nome social. Tomamos como ponto de partida o Decreto $\mathrm{N}^{\mathrm{o}} 8.727$, que dispõe sobre o uso do nome social por pessoas trans ${ }^{4}$ em órgãos públicos federais, além de dez notícias do jornalismo online, publicadas após o decreto e que tematizam a questão do nome social. Voltamos-nos mais especificamente para a análise do conteúdo temático desses enunciados, buscando compreender de que modo esse elemento dialoga com discursos outros e como contribuem para a constituição dos enunciados e de uma noção mais ampla relacionada à identidade de pessoas trans. $\mathrm{O}$ olhar para o conteúdo temático de um enunciado viabiliza uma maior compreensão do gênero do discurso de que faz parte, além das intenções e valorações do seu interlocutor.

Feitos esses apontamentos acerca da perspectiva epistemológica aqui assumida, iniciamos uma breve contextualização da promulgação do enunciado entendido como grande tema desta pesquisa, o Decreto $\mathrm{N}^{\circ}$ 8.727. Esse decreto, publicado em 28 de abril de 2016, foi assinado pela presidenta eleita Dilma Rousseff e pode ser compreendido como uma resposta da esfera oficial/política aos anseios e mobilizações cotidianas da população trans e ALGBTQI+ ${ }^{5}$ no Brasil.

Nesta pesquisa, assumimos que os gêneros do discurso se ancoram nas intersecções espaço-temporais em que se constituem; compreendemos, portanto, o cronotopo como elemento organizador dos acontecimentos (BAKHTIN, 2014[19341935]). Os enunciados em análise - o Decreto $\mathrm{N}^{\circ} 8.727 / 2016$ e notícias do jornalismo online - se inserem em esferas discursivas distintas, a jurídico-governamental e a

3 A pesquisa aqui empreendida compõe um estudo iniciado por Guilherme (2017) e desenvolvido em Guilherme (2018) e Guilherme (2019), no prelo.

4 Neste estudo utilizamos o termo trans (pessoa trans, sujeito trans) como conceito guarda-chuva, incluindo os sujeitos que vivenciam papéis de gênero que extrapolam os modelos cisnormativos. Esse grupo é formado predominantemente por travestis e transexuais, mas também inclui quaisquer outros que não se identificam com o gênero que lhes foi atribuído no nascimento (JESUS, 2012a). Não deixamos de levar em conta o fato de que não há consenso quanto à terminologia para esse grupo no Brasil, como ocorre nos Estados Unidos com transgender. Nossa escolha foi a de não assumir a tradução de transgender - transgêneros - pois entendemos que esse termo diminui a carga semântica de outros como travestis e transexuais, com significação ampla em campos teóricos e políticos e que fazem também relação com a luta desses grupos, optando, desse modo, pelo uso do sufixo trans para fazer menção a esse grupo de pessoas.

5 A escolha por essa sigla se deu uma vez que entendemos que ela inclui um grande número de possíveis orientações sexuais e identidades de gênero. Não pretendemos, com isso, limitar ou excluir quaisquer outras possibilidades existentes nesse complexo espectro de sexualidades e vivências de gênero. Para uma leitura mais aprofundada acerca da trajetória da comunidade ALGBTQI+, recomendamos a leitura de Lau (2018). 
jornalística. Partindo da perspectiva aqui assumida, entende-se que essas esferas, apesar de diferentes, não funcionam de modo independente e que há constantes interferências entre elas, além de relações dialógicas que as perpassam. Isso quer dizer que cada enunciado carrega as peculiaridades e especificidades do espaço-tempo em que foi empreendido e que há influência de um enunciado nos demais, com certa imbricação entre as esferas discursivas.

O Decreto $\mathrm{N}^{\mathrm{o}} 8.727 / 2016$ foi publicado em abril de 2016, porém, não podemos afirmar que a concretização desse tenha ocorrido de forma espontânea ou não-motivada, pelo contrário, entendemos que a promulgação do decreto representa uma resposta da esfera oficial - a ideologia oficial - às demandas e pressões das ideologias cotidianas (BAKHTIN; VOLOCHÍNOV, (2014[1929]). Na perspectiva bakhtiniana, o processo de constituição ideológica se dá a partir das relações dialógicas entre a ideologia oficial e a ideologia do cotidiano: aquela representando os valores estabelecidos socialmente, como religião, ciência e lei e esta representando as relações sociais entre sujeitos organizados na vida cotidiana. Assim, as mobilizações das populações ALGBTQI+, os movimentos sociais, coletivos e articulação online por parte desses grupos, progressivamente pressionaram e interferiram na esfera oficial, ocasionando em uma série de respostas, dentre elas a publicação do referido decreto. Assim, entendemos que "as demandas da população trans se tornam lei (discurso oficial) a partir da pressão das ideologias do cotidiano sobre a ideologia oficial, em uma relação tensa e intensa entre essas bases ideológicas" (GUILHERME, 2017, p. 14).

Dito isso, damos continuidade ao presente estudo, seguindo para uma breve delineação do percurso metodológico aqui empreendido na seção seguinte, com posterior análise do conteúdo temático dos enunciados em tela e, por fim, com algumas das considerações finais aqui alcançadas.

\section{PERCURSO METODOLÓGICO}

Como mencionado anteriormente, este estudo busca analisar os conteúdos temáticos de onze enunciados das esferas jurídico-governamental e jornalística, o Decreto $\mathrm{N}^{\circ} 8.727 / 2016$ e dez notícias do jornalismo online, por meio de uma análise dialógica do discurso. Para tanto, empreendemos uma pesquisa que se caracteriza como sendo qualitativa de cunho interpretativista, uma vez que se ocupa de realidades não quantificáveis. Para Minayo (2013, p. 21), a pesquisa qualitativa "trabalha com o 
universo dos significados, dos motivos, das aspirações, das crenças, dos valores e das atitudes".

Além disso, este estudo se insere no campo teórico da Linguística Aplicada (LA), mais especificamente no campo da LA indisciplinar/contemporânea, vertente essa que visa "criar inteligibilidade sobre problemas sociais em que a linguagem tem um papel central" (MOITA LOPES, 2006, p. 14). Considerando essa intenção em voltar o olhar para os discursos sobre a identidade de sujeitos trans a partir de discussões sobre o nome social fomentadas pelo Decreto № 8.727/2016, o aporte epistemológico da LA torna-se essencial. Além disso, esta pesquisa pretende também problematizar questões identitárias sobre a realidade das pessoas trans, buscando "construir a compreensão da vida social com eles em suas perspectivas e vozes, sem hierarquizá-los" (MOITA LOPES, 2006, p. 96).

Cabe destacar que uma análise que se propõe como dialógica deve se voltar para as práticas discursivas materializadas em enunciados concretos, levando-se em conta seus contextos de enunciação. Para Bakhtin (2015[1979]), a linguagem em uso se manifesta a partir de enunciados concretos, que são mobilizados por sujeitos socialmente inseridos e em constante interação com outros sujeitos. Assumimos, portanto, a noção de texto como enunciado, entendendo que os enunciados não existem individualmente, e que estão em constante diálogo com enunciados outros, propiciando, dessa forma, a construção de sentidos.

Partindo do exposto acerca do contexto teórico-metodológico aqui assumido, seguimos para a delineação dos enunciados em análise nesta pesquisa. Além do já mencionado Decreto $N^{\circ} 8.727 / 2016$, que busca regulamentar o uso do nome social por pessoas trans em órgãos públicos federais, tomamos também dez notícias do jornalismo online. No Quadro 1, abaixo, listamos os enunciados selecionados.

Quadro 1 - Dados da pesquisa (A Autora, 2019)

\begin{tabular}{|c|l|l|c|}
\hline DADO & \multicolumn{1}{|c|}{ TÍTULO } & FONTE & $\begin{array}{c}\text { DATA DE } \\
\text { PUBLICAÇÃO }\end{array}$ \\
\hline Decreto & Decreto No 8.727, de 28 de abril de 2016 & $\begin{array}{l}\text { Governo } \\
\text { Federal }\end{array}$ & $28 / 04 / 16$ \\
\hline N1 & $\begin{array}{l}\text { Transexuais e travestis poderão usar nome social no } \\
\text { serviço público federal }\end{array}$ & G1 & $28 / 04 / 16$ \\
\hline
\end{tabular}


REVISTA X, Curitiba, volume 14, n.4,p. 107-119, 2019

\begin{tabular}{|c|c|c|c|}
\hline $\mathrm{N} 2$ & $\begin{array}{l}\text { Dilma assina decreto que permite transexuais usarem } \\
\text { nome social em órgãos federais }\end{array}$ & notícias UOL & $28 / 04 / 16$ \\
\hline N3 & $\begin{array}{l}\text { Deputados de dez partidos querem vetar nome social } \\
\text { de travestis no serviço público }\end{array}$ & Estadão & $19 / 05 / 16$ \\
\hline N4 & $\begin{array}{l}\text { Deputados de } 10 \text { partidos tentam vetar nome social } \\
\text { de travestis no serviço público }\end{array}$ & notícias UOL & $19 / 05 / 16$ \\
\hline N5 & $\begin{array}{l}\text { No AP, travestis e transexuais podem usar nome } \\
\text { social para serviços de saúde }\end{array}$ & G1 & $18 / 04 / 17$ \\
\hline N6 & $\begin{array}{l}\text { UFGD respeita decreto e adota nome social para } \\
\text { travestis e transexuais }\end{array}$ & $\begin{array}{l}\text { Campo } \\
\text { Grande News }\end{array}$ & $14 / 12 / 16$ \\
\hline N7 & $\begin{array}{l}\text { Mulher transexual é impedida de embarcar em } \\
\text { aeroporto de SC ao usar nome social }\end{array}$ & G1 & $18 / 08 / 17$ \\
\hline N8 & $\begin{array}{l}\text { Jovem trans é impedida de abrir crediário em loja } \\
\text { com nome social: 'Humilhada', diz }\end{array}$ & G1 & $11 / 05 / 17$ \\
\hline N9 & $\begin{array}{l}\text { Deputado goiano compara nome social a "apelido" e } \\
\text { pede direito igual para héteros }\end{array}$ & Jornal Opção & $20 / 07 / 17$ \\
\hline N10 & $\begin{array}{l}\text { Mulher travesti discute com juíza e promotor para ter } \\
\text { nome social respeitado em audiência no ES }\end{array}$ & G1 & $28 / 07 / 17$ \\
\hline
\end{tabular}

Entendemos o decreto como sendo um enunciado motivador dos demais enunciados selecionados, uma vez que todas as notícias tratam da questão do nome social, também motivadas pela publicação do decreto, estabelecendo relações de diálogo entre os enunciados. Após a promulgação do Decreto № 8.727, em 28 de abril de 2016, várias notícias foram publicadas narrando o evento de sua publicação. Para esta pesquisa, selecionamos dois enunciados publicados no mesmo dia que o decreto, noticiando sua promulgação (N1 e N2), duas notícias que narram uma tentativa de anulação desse decreto (N3 e N4), outras duas que abordam a implementação do uso do nome social a partir do Decreto $\mathrm{N}^{\mathrm{o}} 8.727$ (N5 e N6) e quatro notícias em que houve impedimento ou não reconhecimento do uso do nome social (N7, N8, N9 e N10).

Diversos são os vieses que uma análise pode seguir. No campo dialógico dos estudos da linguagem, tomamos os enunciados como objetos de análise. Os enunciados são compostos por três elementos principais, o conteúdo temático, o estilo e a composição e analisados sob a ótica da análise dialógica do discurso. Destacamos que a proposta teórico-metodológica para análise de textos criada a partir dos estudos do 
REVISTA X, Curitiba, volume 14, n.4,p. 107-119, 2019

Círculo de Bakhtin, a ADD, como afirma Brait (2006, p. 60), não trabalha com "categorias a priori, aplicáveis de forma mecânica a textos e discursos, com a finalidade de compreender formas de produção de sentido num dado discurso, numa dada obra, num dado texto", ou seja, a partir do entendimento de alguns conceitos teóricos sobre a teoria de linguagem aqui empreendida, assumimos uma postura dialógica frente aos dados, o que será elaborado na seção seguinte.

\section{O OLHAR PARA O CONTEÚDO TEMÁTICO DOS ENUNCIADOS}

Em uma pesquisa ancorada epistemologicamente na perspectiva dialógica da linguagem, o olhar para o conteúdo temático, ou tema, de um enunciado viabiliza uma maior compreensão do gênero do discurso de que faz parte, além de sua função social, as intenções e posicionamentos do interlocutor. Segundo Acosta Pereira (2008, p. 29), "o conteúdo temático é compreendido como o objeto de sentido valorado no discurso, isto é, o conteúdo tematizado que se desenvolve no enunciado a partir da interação".

Além disso, o conteúdo temático abarca o aspecto discursivo de um enunciado e, para ser compreendido, deve ir além de suas fronteiras linguísticas. O tema "[...] se apresenta como a expressão de uma situação histórica concreta que deu origem à enunciação" (BAKHTIN; VOLOCHÍNOV, 2014[1929], p. 133) e, além disso, se vincula a esse contexto histórico, envolvendo diversos fatores, incluindo o espaçotempo da interação, os interlocutores envolvidos, além da esfera discursiva em que se insere.

Compreendendo, portanto, que o tema de um enunciado é sempre único, entendemos que mesmo em exemplares de um mesmo gênero, o tema nunca se repete, uma vez que "todo gênero tem um conteúdo temático determinado: seu objeto discursivo e finalidade discursiva, sua orientação de sentido específico para com ele e os outros participantes da interação" (RODRIGUES, 2005, p. 167). Entende-se ainda que o conteúdo temático não trata somente do assunto de um enunciado em si, mas envolve atribuições de sentidos outras e que pode ser caracterizado pela "contemporaneidade, efemeridade e proximidade tempo-espacial dos fatos e dos acontecimentos a serem noticiados" (ACOSTA PEREIRA, 2008, p. 99).

Nos dados em tela, grosso modo, o principal conteúdo temático encontrado é relacionado ao nome social. Esse tema é discursivizado e perpassa todas as dez notícias online, a partir da promulgação do Decreto $N^{\circ} 8.727$, e é abordado por diferentes vieses. Dentre os dados em análise, as principais regularidades encontradas foram as seguintes: 
i) nome social explicado a partir do Decreto $\mathrm{N}^{\circ} 8.727$; ii) divulgação do direito ao uso do nome social; iii) implementação do uso do nome social; iv) direito ao uso do nome social questionado; v) impedimento do uso do nome social; vi) não reconhecimento do nome social. No Quadro 2, a seguir, apresentamos essas regularidades, associando-as às notícias em que são predominantes, além de um fragmento de cada uma delas, a título de exemplificação.

Quadro 2 - Regularidades do conteúdo temático das notícias (A Autora, 2019)

\begin{tabular}{|c|c|c|}
\hline $\begin{array}{c}\text { REGULARIDADE DO } \\
\text { CONTEÚDO TEMÁTICO }\end{array}$ & NOTÍCIA & EXCERTO DA NOTÍCIA \\
\hline \multirow[t]{2}{*}{$\begin{array}{l}\text { Nome social explicado a } \\
\text { partir do Decreto N. } 8.727\end{array}$} & N1 & $\begin{array}{l}\text { A presidente Dilma Rousseff assinou nesta quinta-feira } \\
\text { (28) um decreto que autoriza a população LGBT } \\
\text { (lésbicas, gays, bissexuais, travestis e transexuais) a } \\
\text { utilizar o chamado "nome social" nos órgãos do serviço } \\
\text { público federal, como ministérios, universidades } \\
\text { federais e empresas estatais }\end{array}$ \\
\hline & $\mathrm{N} 2$ & $\begin{array}{l}\text { A presidente Dilma Rousseff assinou nesta quinta-feira } \\
\text { (28) decreto que permite transexuais e travestis usarem } \\
\text { seu nome social em todos os órgãos públicos, autarquias } \\
\text { e empresas estatais federais. }\end{array}$ \\
\hline $\begin{array}{l}\text { Divulgação do direito ao uso } \\
\text { do nome social }\end{array}$ & N5 & $\begin{array}{l}\text { Uso do nome social é garantido com base no decreto } \\
8.727 / 16 \text {, do Governo Federal. ONG entregou portaria } \\
\text { em hospitais e postos de saúde de Macapá }\end{array}$ \\
\hline $\begin{array}{l}\text { Implementação do uso do } \\
\text { nome social }\end{array}$ & N6 & $\begin{array}{l}\text { A UFGD (Universidade Federal da Grande Dourados) } \\
\text { decidiu optar pelo uso do nome social por estudantes } \\
\text { de Graduação e Pós-graduação da instituição. }\end{array}$ \\
\hline \multirow{3}{*}{$\begin{array}{l}\text { Direito ao uso do nome social } \\
\text { questionado }\end{array}$} & N3 & $\begin{array}{l}\text { Menos de um mês após ser decretado pela presidente } \\
\text { afastada Dilma Rousseff (PT), o uso do nome social de } \\
\text { travestis e transexuais nos órgãos da administração } \\
\text { pública direta e indireta é questionado por } \\
\text { parlamentares. }\end{array}$ \\
\hline & N4 & $\begin{array}{l}\text { Deputados de dez partidos apresentaram nesta quarta- } \\
\text { feira (18) um projeto para suspender o direito de } \\
\text { transexuais e travestis a usarem seu nome social nos } \\
\text { órgãos públicos do governo federal. }\end{array}$ \\
\hline & N9 & $\begin{array}{l}\text { O deputado federal goiano João Campos (PRB), que é } \\
\text { autor do projeto polêmico sobre a "cura gay", quer } \\
\text { sustar o decreto que concede a travestis e transexuais } \\
\text { o direito de serem identificados pelo nome social nas } \\
\text { entidades da administração pública federal. }\end{array}$ \\
\hline \multirow{2}{*}{$\begin{array}{l}\text { Impedimento do uso do nome } \\
\text { social }\end{array}$} & N7 & $\begin{array}{l}\text { Uma mulher transexual foi impedida de embarcar no } \\
\text { Aeroporto Lauro Carneiro de Loyola, em Joinville, na } \\
\text { manhã de quinta-feira (16), porque o nome social que } \\
\text { constava na passagem aérea era diferente do nome } \\
\text { presente nos documentos de identificação. }\end{array}$ \\
\hline & N8 & $\begin{array}{l}\text { Uma mulher trans de São Carlos (SP) foi impedida de } \\
\text { abrir um crediário utilizando seu nome social em uma } \\
\text { loja de departamentos da cidade. Mesmo apresentando o } \\
\text { RG, Leona Zanforlin não conseguiu dar continuidade ao } \\
\text { procedimento. }\end{array}$ \\
\hline
\end{tabular}


REVISTA X, Curitiba, volume 14, n.4,p. 107-119, 2019

\begin{tabular}{|l|l|}
\hline \multirow{2}{*}{$\begin{array}{l}\text { Não reconhecimento do nome } \\
\text { social }\end{array} \quad \begin{array}{l}\text { Um trecho do artigo } 6^{\circ} \text { do decreto presidencial 8.727, de } \\
\text { abril de 2016, diz que "a pessoa travesti ou transexual } \\
\text { poderá requerer, a qualquer tempo, a inclusão de seu } \\
\text { nome social em documentos oficiais". Mesmo assim, a } \\
\text { mulher travesti Deborah Sabará conta que precisou } \\
\text { entrar em um debate com uma juíza e um promotor } \\
\text { para que seu nome social constasse em um } \\
\text { documento oficial durante uma audiência judicial no } \\
\text { Espírito Santo. }\end{array}$} \\
\hline
\end{tabular}

Como pode ser observado no quadro acima, nas notícias N1 e N2 o nome social é explanado a partir do Decreto N. 8.727, que dispõe sobre o seu uso por pessoas trans em órgãos públicos federais. As notícias narram a publicação do decreto e abordam a questão do nome social com o objetivo de dar contexto e explicar o conteúdo do documento para os leitores. Nos enunciados N5 e N6, temos notícias que narram a divulgação do direito ao uso do nome social e a implementação do uso do nome social, respectivamente. Em N5, há apontamentos sobre o uso do nome social em serviços de saúde, mais especificamente a partir da Portaria 1.820/2002, que trata dos direitos e deveres dos usuários da saúde pública. Nesse documento, há determinação de que todos os cidadãos possuem direito a receber um atendimento acolhedor e com respeito junto ao Sistema Único de Saúde, independentemente de fatores diversos, incluindo orientação sexual e identidade de gênero. Em N6, é noticiada a regulamentação do uso do nome social na Universidade Federal da Grande Dourados (MS), por meio de resolução interna publicada em dezembro de 2016, a partir de reenunciação do Decreto $\mathrm{N}^{\mathrm{o}} 8.727$, promulgado em abril desse mesmo ano.

Nos primeiros enunciados analisados, observamos como a noção de nome social perpassa o conteúdo temático dos enunciados, sendo esse entendido como um direito da pessoa trans em ser reconhecida socialmente pelo gênero com que se identifica. Por outro lado, nos demais dados, é possível observar acentos temático-valorativos depreciativos e de rejeição à identidade trans, com o questionamento do direito ao uso do nome social, além do impedimento e do não reconhecimento do nome social por pessoas trans. Sobre esse ponto, destacamos, conforme Bakhtin e Volochínov (2014[1979], p. 179), que:

Toda palavra usada na fala real possui não apenas tema e significação no sentido objetivo, de conteúdo, desses termos, mas também um acento de valor ou apreciativo, isto é, quando um conteúdo objetivo é expresso (dito ou escrito) pela fala viva, ele é sempre acompanhado por um acento apreciativo determinado. Sem acento apreciativo, não há palavra. 
REVISTA X, Curitiba, volume 14, n.4,p. 107-119, 2019

Nos enunciados N3 e N4, por exemplo, há um questionamento do direito ao uso do nome social. Cabe destacar que após a publicação do Decreto $\mathrm{N}^{\circ} 8.727$ houve grande reação na esfera política, reação essa manifestada pelo protocolo do Projeto de Decreto Legislativo (PDC) 395/2016. Esse documento foi assinado por 29 deputados e visa sustar o decreto assinado por Dilma Rousseff. Assim, os enunciados N3 e N4 narram a publicação desse PDC, que questiona o nome social enquanto direito da população trans. Nesse documento, que busca sustar o Decreto $N^{o}$ 8.727, há justificativas de teor legal, porém, como o conteúdo temático de um dado enunciado deve ser relacionado ao contexto social em que se insere e aos seus interlocutores, chamamos atenção para o fato de que grande parte dos deputados que o assinam fazem parte da Frente Parlamentar Evangélica, a chamada bancada evangélica, incluindo o deputado João Campos (PRB), autor do PDC 395/2016. Ressaltamos que essas considerações foram tecidas a partir do lugar histórico desta pesquisadora e de seu olhar para a análise das peculiaridades discursivas dos enunciados analisados, conforme norte teóricometodológico da ADD (BRAIT, 2006).

O fato mencionado faz emergir questionamentos em relação às intenções reais pretendidas com a publicação desse documento, seriam de fato interesses legais e jurídicos? Sabe-se que a bancada religiosa promove, no campo político, articulação contrária a questões como igualdade racial, igualdade de gênero, violência de gênero e direitos da comunidade ALGBTQI+, a sua postura perante a esses temas indica a demarcação ideológica do posicionamento desse grupo, para além da esfera política, adentrando questões de moral e religiosidade. A regularidade temática de questionamento do direito ao uso do nome social está presente também no enunciado N9, em que o deputado supramencionado João Campos (PRB), autor da PDC 395/2016, ironiza o uso do nome social ao compará-lo com um apelido.

Um outro ponto de vista pode ser observado nos demais enunciados (N7, N8 e N10). Apesar de os temas principais serem o impedimento do uso do nome social e o não reconhecimento de seu uso, destaca-se que nesses há a voz de sujeitos trans narrando seu ponto de vista em relação a essas situações. Em N8 e N9 há, respectivamente, relatos de mulheres trans impedidas de utilizarem seus nomes sociais em um aeroporto e em uma loja de departamentos. Já em N10, uma mulher travesti, conselheira estadual de Direitos Humanos, descreve a situação de constrangimento que passou ao ter seu nome social não reconhecido por parte de uma juíza em uma audiência na $1^{\text {a }}$ Vara Criminal de Vitória (ES). Nesses três casos, é a própria pessoa trans quem 
REVISTA X, Curitiba, volume 14, n.4,p. 107-119, 2019

relata as situações de impedimento do uso do nome social, mas também há um destaque para a importância de seu uso e as consequências do seu impedimento.

Feitos esses apontamentos a respeito dos conteúdos temáticos dos enunciados em tela, além da tentativa de categorização desses a partir de algumas regularidades encontradas, reiteramos a importância do estudo desse elemento constituinte dos enunciados a fim de bem compreender seu sentido além do contexto sócio-histórico em que são enunciados. A seguir, seguimos para a seção final deste estudo, em que trazemos nossas considerações finais.

\section{CONSIDERAÇÕES FINAIS}

Tomamos como ponto de partida para este estudo a publicação do Decreto $\mathrm{N}^{\circ}$ 8.727, em abril de 2016, que dispõe sobre o uso do nome social por pessoas trans em órgãos públicos federais. Entendemos a promulgação desse decreto como uma resposta da esfera jurídico-governamental aos anseios e mobilizações sociais da população trans e ALGBTQI+. Após a publicação do referido decreto, uma série de discursos outros surgiram, dentre eles as dez notícias selecionadas para análise nesta pesquisa. Ressaltamos que o uso do nome social é uma demanda do movimento trans e que, por meio dele, esses sujeitos buscam reconhecimento da sua identidade de gênero em seus círculos sociais e profissionais. Ainda, o nome social não é uma solução definitiva e funciona, segundo Bento (2012), como uma gambiarra legal, que visa dar cidadania e dignidade às pessoas trans que não conseguiram ainda retificação dos seus registros civis.

A partir de uma análise dialógica do discurso, ancorada pelos escritos do Círculo de Bakhtin, voltamos nosso olhar para o conteúdo temático dos enunciados em tela, uma vez que compreendemos a importância desse elemento para a construção de sentido dos enunciados. Cabe destacar que o tema de um enunciado muda em função das intenções do autor e do auditório, além das suas situações de produção. Para Bakhtin/Volochínov (2014[1929]), o conteúdo temático de um enunciado vai além das formas linguísticas que o compõem e leva em conta também os elementos extraverbais da situação.

A análise aqui empreendida fez emergir algumas regularidades, sobretudo voltadas à questão do nome social. Nos enunciados em tela, temos como conteúdos temáticos centrais: o nome social explicado a partir do Decreto N. 8.727; a divulgação do direito ao uso do nome social; a implementação do uso do nome social; o 
REVISTA X, Curitiba, volume 14, n.4,p. 107-119, 2019

questionamento do direito ao uso do nome social; situações em que há impedimento do uso do nome social e o não reconhecimento do nome social. Dito isso, reiteramos nosso entendimento de que a compreensão e o estudo do conteúdo temático de um enunciado contribui para a construção dos seus sentidos.

\section{REFERÊNCIAS}

ACOSTA PEREIRA, Rodrigo. O gênero jornalístico notícia: dialogismo e valoração. Dissertação de Mestrado. Universidade Federal de Santa Catarina. Florianópolis, 2008.

BAKHTIN, Mikhail M. Estética da criação verbal. Tradução Paulo Bezerra. 6. ed. São Paulo, Martins Fontes, 2015[1979].

BAKHTIN, Mikhail M. Os gêneros do discurso. Tradução do russo por Paulo Bezerra. Editora 34: São Paulo, 2016 [1952-1953].

BAKHTIN, Mikhail. Problemas da poética de Dostoiévski. Tradução do russo, notas e prefácio de Paulo Bezerra. 5 ed. Rio de Janeiro: Forense Universitária, 2015[1963].

BAKHTIN, Mikhail. Questões de literatura e estética: a teoria do romance. Tradução de Aurora Fornoni Bernadini [et al]. 7ed. São Paulo: Hucitec, 2014[1934-1935]

BAKHTIN, Mikhail M.; VOLOCHÍNOV, Valentin N. Marxismo e filosofia da linguagem: problemas fundamentais do método sociológico na ciência da linguagem. 16ed. Tradução do francês por Michel Lahud e Yara F. Vieira. São Paulo: Hucitec, 2014[1929].

BENTO, Berenice. Identidade de gênero: entre a gambiarra e o direito pleno. Carta Potiguar, 21 set. 2012. Disponível em: $<$ http://www.cartapotiguar.com.br/2012/05/29/identidade-degenero-entre-agambiarra-eo-direito-pleno>. Acesso em: 15 Nov. 2018.

BRAIT, Beth. Uma perspectiva dialógica de teoria, método e análise. In: Gragoatá. Niterói, n. 20, p. 47-62, 1. sem. 2006

GUILHERME, Maria Lígia Freire. Os discursos sobre a identidade de sujeitos Trans em textos online: neutralização, enquadramento e relações dialógicas, 2017. Dissertação (Mestrado em Estudos de Linguagens) - Universidade Tecnológica Federal do Paraná, Curitiba.

GUILHERME, Maria Lígia Freire. O nome social de sujeitos trans em evidência: uma análise dialógica do Decreto N. 8.727/2016. Letra Magna - Revista de Divulgação Científica em Língua Portuguesa, Linguística e Literatura, ano 14, n. 22, 2018.

GUILHERME, Maria Lígia Freire. Nome social é apelido? Diálogos a partir do decreto 8.727/2016. In: LAU, Héliton Diego; SILVEIRA, Éderson Luís (orgs.). Raça, gênero e sexualidade em perspectivas discursivas: teorias e análises. v. 1. São Paulo: Pimenta Cultural, 2019 (no prelo). 
JESUS, Jaqueline G. Guia técnico sobre pessoas transexuais, travestis e demais transgêneros para formadores de opinião. Brasília, Fundação Biblioteca Nacional, 2012a.

LAU, Heliton Diego. Pelo direito e orgulho de ser heterossexual no terceiro domingo de dezembro. São Paulo: Pimenta Cultural, 2018.

MINAYO, Maria Cecilia de Souza (Org.). Pesquisa social: teoria, método e criatividade. Petrópolis: Vozes, 2013.

MOITA LOPES, Luiz Paulo da (org). Por uma linguística aplicada indisciplinar. São Paulo: Parábola Editorial, 2006.

RODRIGUES, Rosângela Hammes. "Os gêneros do discurso na perspectiva dialógica da linguagem: a abordagem do Círculo de Bakhtin”. In: Adair Bonini; José Luiz Meurer; Désirée Mora-Roth. (Org.). Gêneros: teoria, métodos, debates. $1^{\mathrm{a} e d . S a ̃ o ~ P a u l o: ~ P a r a ́ b o l a, ~}$ 2005, p. 152-183.

VOLOCHÍNOV, Valentin N. A construção da enunciação e outros ensaios. Tradução João Wanderley Geraldi. São Carlos: Pedro \& João Editores, 2013[1930]. 